ORIGINAL ARTICLE

\title{
Severe acute respiratory syndrome in Singapore
}

\author{
J Puthucheary, D Lim, I Chan, O M Chay, P Choo
}

Arch Dis Child 2004;89:551-556. doi: 10.1136/adc.2003.039420

See end of article for authors' affiliations .....................

Correspondence to: Dr J Puthucheary, Department of Paediatric Medicine, KK Women's and Children's Hospital, 100 Bukit Timah Road, Singapore 229899; jani@kkh.com.sg

Accepted 27 October 2003

\begin{abstract}
Aims: To describe the epidemiological and clinical features of paediatric severe acute respiratory syndrome (SARS) in Singapore.

Methods: The following data were retrospectively collected from the case records of all 71 patients (aged 7 months to 14 years) admitted from 23 March to 22 May 2003 to the SARS paediatric unit: patient demographics, contact history, clinical features, physiological parameters, investigations, treatment, and outcome. Using WHO criteria there were seven probable (P), 23 suspect (S), and 41 observe (O) cases. Results: Compared to the $O$ cases $P$ patients had a longer mean duration of fever (3.66 (SD 2.3) v 8.57 (SD 2.44) days), lower mean thrombocytopenia (248.3 (SD 82.7) v 173.7 (SD 49.0) $\times 10^{9} /$ I), leucopenia $\left(8.19\right.$ (SD 4.45) $\vee 3.06($ SD 1.02$) \times 10^{9} /$ I), lymphopenia $\left(2.79\right.$ (SD 1.97) $\vee 1.44(S D 0.75) \times 10^{9} /$ I), and neutropenia (4.48 (SD 2.88) v 1.24 (SD 0.43$\left.) \times 10^{9} / \mathrm{l}\right)$. Chest auscultation was abnormal in $71 \%$ of $\mathrm{P}$ patients, with mild crepitations detected. All had abnormal chest radiographs versus $39 \%$ of $\mathrm{S}$ cases, and $27 \%$ of $O$ cases.

Conclusions: There are no distinguishing clinical features of paediatric SARS. The diagnosis is suggested by the paucity of clinical signs with an abnormal chest radiograph, and laboratory evidence of leucopenia, lymphopenia, and thrombocytopenia.
\end{abstract}

$\mathrm{S}$ evere acute respiratory syndrome (SARS) is an emerging disease that has been linked to infection with a new strain of coronavirus $(\mathrm{CoV}) .{ }^{12}$ The infection has spread out from Guangdong province, China, to Hong Kong, ${ }^{3}$ and then a large number of centres around the world. ${ }^{4}$ The first case in Singapore occurred in a traveller that returned from Hong Kong, ${ }^{5}$ and to date there have been more than 200 patients affected on this island. ${ }^{4}$ A much larger number of patients have been admitted and treated at the designated SARS centre, Tan Tock Seng Hospital (TTSH), as part of the efforts to limit the spread of the disease. Prior to the outbreak of SARS, TTSH delivered comprehensive healthcare services, with the exception of maternity, neonatal, and paediatric units. In response to the developing crisis staff from three other centres (KK Women's and Children's Hospital (KKH), National University Hospital (NUH), and Singapore General Hospital (SGH)) collaborated with TTSH in rapidly developing these services on site, and redeploying their staff to man the units. Thus every SARS related paediatric case in Singapore was referred to one centre.

The objectives of this study were: to describe the epidemiological and clinical features of all paediatric SARS related patients in Singapore to date; to describe the treatment given to these patients; and to compare the investigative results and outcomes of SARS and non-SARS patients admitted to the unit.

\section{METHODS}

Paediatric patients admitted to TTSH were all nursed on the same ward. The admission criteria were age less than 12 years, and having a suspected SARS related diagnosis. Adolescent patients aged 13 and above were usually nursed in other wards within the same hospital and were seen by a different medical team. History and clinical examination data was recorded in a standard manner. Data were also routinely collected regarding the contact and travel history, along with information regarding possible family exposure to SARS infection. Laboratory investigations were performed with respect to the SARS related diagnosis as per the prevailing SARS protocol at the time of admission, which was based on
CDC and WHO guidelines. In addition investigations were performed at the discretion of the clinician with respect to other possible non-SARS diagnoses.

Data were collected retrospectively for all patients from the case records, using a standardised proforma. Information was collected on patient demographics, contact history, travel history, family history, clinical features, physiological parameters, investigations, treatment, and outcome. All the case records were reviewed independently by two of the authors.

Patients were classified during their admission into the categories of "probable" (P), "suspect" (S), and "observe" (O), to reflect the likelihood that they had a SARS related condition. Patients in the P category were considered to have SARS; those in the $\mathrm{S}$ group did not meet the clinical case definition, but nevertheless had fever and respiratory symptoms along with an epidemiological link. Patients in the $\mathrm{O}$ group did not meet the clinical, epidemiological, or laboratory definitions at the time, and had been admitted either as a result of concern, or a clustering of illness that turned out to be non-SARS related. The classification was done using the CDC and WHO criteria that were available at the time of admission. ${ }^{6}$ The data for the O group were then compared to the other two categories.

One patient that had been previously classified as probable SARS was not admitted to TTSH. This patient had severe adult respiratory distress syndrome (ARDS) and was not stable for transfer from the paediatric intensive care unit where she was admitted. She was later found to have adenovirus infection; there was no laboratory evidence of SARS, and no epidemiological link. She subsequently died; postmortem analysis revealed no evidence of coronavirus infection. She was not included in this analysis.

As this was a retrospective case review, ethical approval was not sought.

Abbreviations: ARDS, adult respiratory distress syndrome; CoV, coronavirus; $O$, observe; $P$, probable; $S$, suspect; SARS, severe acute respiratory syndrome; TTSH, Tan Tock Seng Hospital 
Table 1 Classification of cases in accordance to $\mathrm{WHO}$ and $C D C$ guidelines

\begin{tabular}{|c|c|c|}
\hline Definition & Clinical features & Travel/contact \\
\hline \multirow{9}{*}{$\begin{array}{l}\text { Probable } \\
\text { SARS }\end{array}$} & Fever $>38^{\circ} \mathrm{C}$ & Positive travel history \\
\hline & AND & $O R$ \\
\hline & $\begin{array}{l}\text { Cough or breathing } \\
\text { difficulty }\end{array}$ & $\begin{array}{l}\text { Close contact history in } \\
\text { preceding } 10 \text { days }\end{array}$ \\
\hline & AND & $O R$ \\
\hline & $\begin{array}{l}x \text { ray changes of } \\
\text { pneumonia }\end{array}$ & $\begin{array}{l}\text { Positive PCR or serological } \\
\text { test for coronavirus }\end{array}$ \\
\hline & $O R$ & \\
\hline & $\begin{array}{l}\text { Respiratory distress } \\
\text { syndrome (RDS) }\end{array}$ & \\
\hline & $O R$ & \\
\hline & $\begin{array}{l}\text { Postmortem examination } \\
\text { findings of RDS without } \\
\text { an identifiable cause }\end{array}$ & \\
\hline \multirow{3}{*}{$\begin{array}{l}\text { Suspect } \\
\text { SARS }\end{array}$} & Fever $>38^{\circ} \mathrm{C}$ & Positive travel \\
\hline & AND & OR \\
\hline & $\begin{array}{l}\text { Cough or breathing } \\
\text { difficulty }\end{array}$ & $\begin{array}{l}\text { Close contact history in } \\
\text { preceding } 10 \text { days }\end{array}$ \\
\hline $\begin{array}{l}\text { Observation } \\
\text { for SARS (1) }\end{array}$ & $\begin{array}{l}\text { Atypical pneumonia } \\
\text { pending confirmatory } \\
\text { investigations and } \\
\text { response to antibiotics }\end{array}$ & Nil \\
\hline $\begin{array}{l}\text { Observation } \\
\text { for SARS (2) }\end{array}$ & Fever $>38^{\circ} \mathrm{C}$ & $\begin{array}{l}\text { Positive travel history in } \\
\text { preceding } 10 \text { days }\end{array}$ \\
\hline $\begin{array}{l}\text { Observation } \\
\text { for SARS (3) }\end{array}$ & $\begin{array}{l}\text { Unexplained fever } \\
>38^{\circ} \mathrm{C}\end{array}$ & $\begin{array}{l}\text { Clustering of two or more } \\
\text { cases in same work area in } \\
\text { a healthcare facility, home, } \\
\text { same workplace, etc }\end{array}$ \\
\hline $\begin{array}{l}\text { Observation } \\
\text { for SARS (4) }\end{array}$ & $\begin{array}{l}\text { Unexplained fever where } \\
\text { the ID physician has } \\
\text { some suspicion of SARS }\end{array}$ & Nil \\
\hline Observation & $\begin{array}{l}\text { Fever, features do not } \\
\text { appear suggestive of } \\
\text { SARS }\end{array}$ & Nil \\
\hline Death & $\begin{array}{l}\text { Death on arrival to } \\
\text { hospital due to } \\
\text { pneumonia without an } \\
\text { identifiable cause } \\
\text { OR } \\
\text { Postmortem findings of RDS }\end{array}$ & $\begin{array}{l}\text { Nil } \\
S\end{array}$ \\
\hline
\end{tabular}

\section{RESULTS}

Seventy one patients, aged 7 months to 14 years (two patients aged 13 and 14 years were admitted to the paediatric unit; they were siblings of younger patients), were admitted from 23 March to 22 May 2003.

\section{Categorisation}

The cases were categorised using criteria based on WHO and CDC guidelines available at the time of admission. This status was updated if there was any significant change in condition or laboratory result. The categorisation was also confirmed at discharge. As part of the study all the cases were reviewed by two of the authors and recategorised using the prevailing criteria (table 1). In the final exercise, three $O$ cases were reclassified as S, six S cases were reclassified as $\mathrm{O}$, and one $\mathrm{P}$ case was designated as non-SARS. This last patient had respiratory secretions that were positive for adenovirus; there was no laboratory evidence of coronavirus infection, and no epidemiological link to a SARS case. No patient was reclassified as P. Analysis of the data was performed after the recategorisation.

\section{Demographics}

There was an over-representation of males in the cohort; while this was also seen in the $\mathrm{S}$ and $\mathrm{O}$ categories, the reverse was true in the P patients (table 2 ). The median age was 4.88 years (0.59 to 14.11$)$; O 5.68 years, S 4.11 years, and P 4.59 years. Age was determined by counting days from birth to admission.

\section{Contact and exposure}

All paediatric $\mathrm{P}$ patients had a definite contact history with an adult P SARS case. All these contacts occurred in the home or community. No $\mathrm{P}$ cases had exposure from a hospital, healthcare worker, or while travelling. Thirty four per cent of the O patients and $30 \%$ of the S patients had a history of contact with a probable or suspect case.

In the cohort a total of $27(38 \%)$ patients had a history of contact with a probable or suspect SARS case before presentation. Of these children, the final categorisation was $\mathrm{P}=7(26 \%), \mathrm{S}=6(22 \%), \mathrm{O}=14(51 \%)$.

There were 44 patients with no known contact. In this group there were no $\mathrm{P}$ cases, $16 \mathrm{~S}$, and $28 \mathrm{O}$. Of these patients, 19 had travelled to a SARS affected country prior to presentation, nine had household contacts that had visited a hospital, seven were children of healthcare workers, and three had visited a hospital. There were four cases admitted as a result of clustering of febrile illness (that is, within a family or school), two cases of atypical pneumonia, and two cases with exposure to a wholesale centre that was known to have had an outbreak of SARS.

All of the seven paediatric SARS cases occurred within the setting of a family cluster. In one instance the patient was exposed to an adult and two teenagers from another family cluster. There was no documented child-to-child or child-toadult transmission, despite exposure (fig 1).

\section{Presentation}

In the $\mathrm{P}$ group the range of possible incubation periods was 1-6 days for six of the patients. One patient had a possible incubation period of $1-12$ days, but this is likely to be inaccurate as the child was exposed to the same contact for several days consecutively (table 3 ). All probable SARS patients presented with fever as the first symptom, versus $83 \%$ of S, and $85 \%$ of O (cough, rhinorrhoea, or sore throat was the first symptom for the other cases). The temperature at presentation, both in the home $(\mathrm{H})$ and at the emergency department (ED) was higher in the $\mathrm{O}\left(\mathrm{H}: 38.8^{\circ} \mathrm{C}(\mathrm{SD} 0.95)\right.$, ED: $\left.38.4^{\circ} \mathrm{C}(\mathrm{SD} 0.79)\right)$ and $\mathrm{S}\left(38.9^{\circ} \mathrm{C}(\mathrm{SD} 0.77), 38.5^{\circ} \mathrm{C}(\mathrm{SD}\right.$ $0.83)$ ) groups compared to the P group ( $\mathrm{H}: 38.3^{\circ} \mathrm{C}$ (SD 0.42 ), ED: $\left.38.0^{\circ} \mathrm{C}(\mathrm{SD} 1.08)\right)$, but this was not significant.

Table 2 Demographics

\begin{tabular}{|c|c|c|c|c|c|c|c|c|}
\hline \multirow[b]{2}{*}{ Category } & \multicolumn{2}{|c|}{ Observed } & \multicolumn{2}{|c|}{ Suspect } & \multicolumn{2}{|c|}{ Probable } & \multicolumn{2}{|l|}{ All } \\
\hline & n & $\%$ & $n$ & $\%$ & $n$ & $\%$ & n & $\%$ \\
\hline Total & 41 & 0.58 & 23 & 0.32 & 7 & 0.10 & 71 & \\
\hline Female & 17 & 0.41 & 7 & 0.30 & 5 & 0.71 & 29 & 0.41 \\
\hline Male & 24 & 0.59 & 16 & 0.70 & 2 & 0.29 & 42 & 0.59 \\
\hline
\end{tabular}



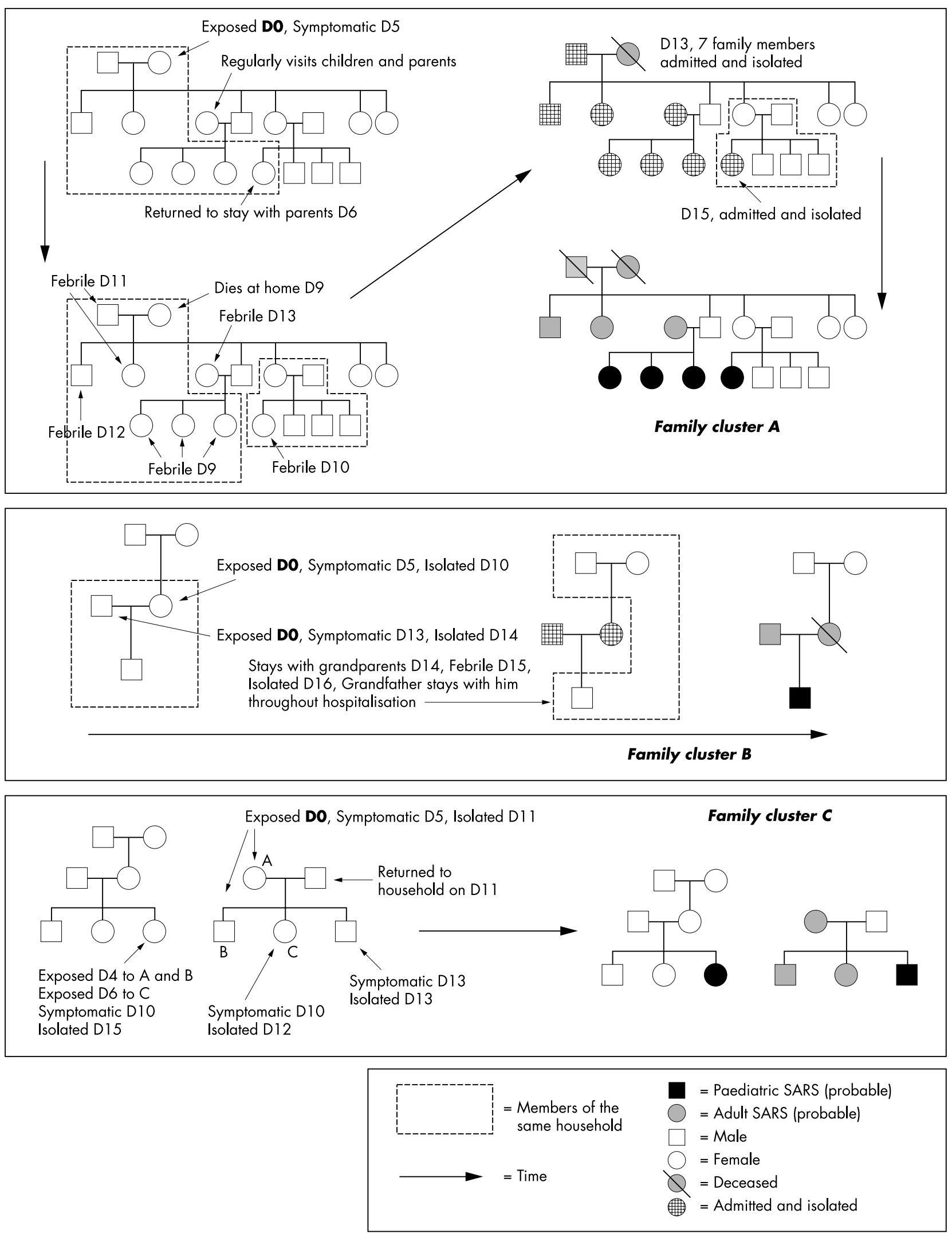

Figure 1 Family clustering of paediatric SARS cases. To protect confidentiality actual dates have not been used. DO represents the first possible date of exposure of the first patient within the family cluster. 
Table 3 Mean days from exposure (first and last) to onset of symptoms

\begin{tabular}{lccc}
\hline Category & Observed & Suspect & Probable \\
\hline $\begin{array}{l}\text { Contact to onset (days) } \\
\text { Min }\end{array}$ & $4.68(3.76)$ & $4.44(2.99)$ & $2.50(2.12)$ \\
Max & $11.88(11.32)$ & $15.33(10.56)$ & $5.71(2.87)$ \\
\hline Results expressed as mean (SD). & &
\end{tabular}

\section{Clinical course}

Some of the probable cases went on to develop cough, myalgia, diarrhoea, vomiting, and rhinorrhoea. These symptoms were also seen in the other patients at some point during the admission. Neither a rash nor conjunctivitis was seen in any paediatric SARS case. None of the patients in the cohort had significant dyspnoea or hypoxaemia (table 4).

There was no significant difference in the maximum temperature recorded in the three groups: O 38.8 (SD 1.08), S 38.9 (SD 1.06), and P 38.9 (SD 0.64). However, the day of illness on which the fever peaked was significantly later in the P cases: O 2.73 (SD 1.86), S 3.83 (SD 3.41), P 5.14 (SD 1.86) ( $t$ test, $\mathrm{O} v \mathrm{P}, \mathrm{p}=0.013$ ). In addition the total number of days with fever was greatest in the P group: O 3.66 (SD 2.3), $\mathrm{S} 6.61$ (SD 7.14), P 8.57 (SD 2.44) ( $t$ test, $\mathrm{O} v \mathrm{P}, \mathrm{p}=0.001)$.

Of the P cases, five $(71 \%)$ had mild crepitations detected; there were no patients with wheeze. The other two patients had normal findings on lung auscultation.

\section{Investigations}

Chest radiographs were abnormal at presentation in five $(71 \%)$ of the P patients. There were nine $(39 \%) \mathrm{S}$ and nine (22\%) O cases with abnormal findings. During the course of the admission all $\mathrm{P}$ patients developed radiographic abnormalities. The radiographic findings varied from minimal airspace opacification to lobar consolidation. There were no "typical" findings, and no patients with a florid ARDS-like chest radiograph. A total of $27 \%$ of the O cases developed changes, and $39 \%$ of the $\mathrm{S}$ cases. At discharge five of the $\mathrm{P}$ patients continued to have radiographic changes, but at follow up the radiographs were all normal.

Although there were some patients with anaemia ( $\mathrm{Hb}$ $<120 \mathrm{~g} / \mathrm{l})$, the lowest haemoglobin recorded was not significantly different between the groups. In the $\mathrm{P}$ patients compared to the $\mathrm{O}$ cases there was significant leucopenia, lymphopenia, and neutropenia at admission and at the lowest recorded total white blood cell count. Thrombocytopenia was also noted in the P cases (tables 5 and 6). The day on which the platelet nadir occurred was also later for P patients.

There was no significant difference in the results for liver function tests, lactate dehydrogenase, and creatine kinase assays.
Four P patients had coronavirus detected by polymerase chain reaction (PCR), three from stool and one from respiratory secretions. Two $\mathrm{P}$ patients did not have PCR performed as they presented before the investigation was available. One P patient was PCR negative, but had very strong epidemiological links to SARS cases (both parents, who had laboratory confirmation of CoV infection) as well as chest radiograph changes.

\section{Treatment}

No patient required mechanical ventilation. One patient required supplemental oxygen for less than 12 hours; he was classified as S. Ribavarin was used for a total of five patients (four P, one S), but only one patient received the full course. Steroid therapy was not used. Almost all patients received antipyretics and symptomatic treatment. A minority required supplemental intravenous fluids.

\section{Outcome}

There were no deaths or admissions to the intensive care unit. All patients were discharged, and at follow up all were asymptomatic. One $\mathrm{P}$ patient subsequently required readmission for bronchiolitis (positive for respiratory syncytial virus). $\mathrm{S}$ and $\mathrm{P}$ cases were discharged under a Home Quarantine Order (HQO); any caregiver who had accompanied the patient during the admission was subjected to the same order.

There were no cases of transmission of infection within the paediatric unit, either from patient to patient, or from patient to healthcare worker. All patients under HQO were followed up daily by phone and then as an outpatient after the end of the order. To date there have been no relapses or cases of transmission after recovery.

All the $\mathrm{O}$ and most of the S ( $82 \%$ ) cases went on to have an alternative diagnosis at discharge. The most common was viral fever or exanthem $(n=19)$, followed by pneumonia $(\mathrm{n}=10)$. All the patients with pneumonia responded to antibiotic therapy. There were also 12 upper respiratory tract infections(including pharyngitis and tonsillitis), five cases of dengue fever, and four cases of gastroenteritis. The remaining cases had bronchitis and asthma.

\section{DISCUSSION}

The paediatric SARS cohort in Singapore has had relatively mild disease compared to the adult population, ${ }^{35}$ and this is in keeping with other reported series of children. ${ }^{7}$ Given the nature of healthcare delivery in Singapore and the heightened awareness of the SARS crisis we are confident that every SARS related paediatric case was referred to and managed in the designated unit.

The case definitions used have been consistent with WHO and CDC guidelines, and although the case definitions changed during the time period covered, the retrospective

Table 4 Symptoms occurring during admission, by category

\begin{tabular}{|c|c|c|c|c|c|c|}
\hline \multirow[b]{2}{*}{ Symptom } & \multicolumn{2}{|c|}{ Observed } & \multicolumn{2}{|c|}{ Suspect } & \multicolumn{2}{|c|}{ Probable } \\
\hline & $\mathbf{n}$ & $\%$ & $\mathbf{n}$ & $\%$ & $\mathbf{n}$ & $\%$ \\
\hline Temperature & 39 & 0.95 & 23 & 1 & 7 & 1 \\
\hline Chills & 2 & 0.05 & 3 & 0.13 & 0 & 0 \\
\hline Cough & 19 & 0.46 & 18 & 0.78 & 2 & 0.29 \\
\hline Myalgia & 4 & 0.10 & 1 & 0.04 & 5 & 0.71 \\
\hline Diarrhoea & 5 & 0.12 & 9 & 0.39 & 2 & 0.29 \\
\hline Rash & 6 & 0.15 & 1 & 0.04 & 0 & 0.00 \\
\hline Vomiting & 6 & 0.15 & 2 & 0.09 & 2 & 0.29 \\
\hline Rhinorrhoea & 9 & 0.22 & 8 & 0.35 & 1 & 0.14 \\
\hline Conjunctivitis & 1 & 0.02 & 0 & 0 & 0 & 0 \\
\hline
\end{tabular}


Table 5 Haematological characteristics

\begin{tabular}{|c|c|c|c|c|c|c|}
\hline & Observed & Suspect & Probable & $\mathbf{p}^{*}$ & pt & All \\
\hline Lowest haemoglobin (g/l) & $125.7(11.4)$ & 119.9 (13.9) & 121 (13.9) & 0.09 & 0.42 & $123.4(12.4)$ \\
\hline \multicolumn{7}{|l|}{ White cell count (WCC) $\times 10^{9} / \mathrm{I}$} \\
\hline Admission & $9.35(4.31)$ & $9.8(3.5)$ & $4.2(1.81)$ & 0.65 & 0.00003 & $8.99(4.17)$ \\
\hline Lowest & $8.19(4.45)$ & $8.88(3.95)$ & $3.06(1.02)$ & 0.52 & 0.000001 & $7.91(4.36)$ \\
\hline \multicolumn{7}{|l|}{ Neutrophil count $\times 10^{9} / \mathrm{I}$} \\
\hline Admission & $5.59(2.68)$ & $6.02(3.51)$ & $2.37(1.22)$ & 0.61 & 0.0001 & $5.41(3.03)$ \\
\hline Lowest & $4.48(2.88)$ & $5.01(3.75)$ & $1.24(0.43)$ & 0.56 & $<0.00001$ & $4.33(3.21)$ \\
\hline \multicolumn{7}{|l|}{ Lymphocyte count $\times 10^{9} / \mathrm{I}$} \\
\hline Admission & $2.72(2.09)$ & $2.7(1.58)$ & $1.38(0.69)$ & 0.95 & 0.003 & $2.58(1.87)$ \\
\hline Lowest & 2.79 (1.97) & $2.75(1.53)$ & $1.44(0.75)$ & 0.92 & 0.0035 & $2.64(1.78)$ \\
\hline \multicolumn{6}{|l|}{ Platelets $\times 10^{9} / \mathrm{I}$} & $3.86(2.78)$ \\
\hline Admission & $267.6(72.6)$ & $281.1(77.9)$ & $190.1(75.3)$ & 0.5 & 0.035 & $264.3(77.8)$ \\
\hline Lowest & 248.3 (82.7) & $269.1(79.0)$ & $173.7(49.0)$ & 0.33 & 0.006 & $251.33(84.86)$ \\
\hline Day of illness lowest platelets & $3.2(2.14)$ & $4.22(3.25)$ & $5.43(1.8)$ & 0.21 & 0.018 & $3.77(2.59)$ \\
\hline $\begin{array}{l}\text { Results expressed as mean (SD). } \\
t \text { test } S \vee O \text {. } \\
\dagger, t \text { test } P \vee O \text {. }\end{array}$ & & & & & & \\
\hline
\end{tabular}

recategorisation confirms that the changes had no impact on the number of SARS cases.

The contact and exposure history in our patients shows no child-to-child or child-to-adult transmission. The reasons for this are not clear; several possibilities have been suggested, including a reduced cytokine response, immunotolerance, and previous immunisations. There is little in our experience or data to suggest an explanation. Although there have been significant concerns regarding the possibility of rapid spread of the disease within schools, this has not been shown. Although many of the SARS patients (adults and children) were epidemiologically linked to outbreaks within hospitals, with appropriate infection control policies and procedures in place the transmission within the hospital environment was stopped.

The incubation periods seen in this study are comparable to those previously reported; ${ }^{7}$ because almost all the children had their contact from a family member, the longest incubation period (12 days) documented is likely to be inaccurate as the child was exposed to the same contact for several days consecutively.

The presence of fever as a characteristic symptom has been documented previously and our findings confirm this. Unfortunately the degree of pyrexia is not helpful in distinguishing SARS within our cohort. The fever peaks later and so at presentation the child may only have a relatively low grade temperature. Several of our P patients "looked well" at admission, and went on to become unwell later. The children who presented "looking toxic" all went on to have an alternative diagnosis. The length of the fever however is likely to be more useful in clinically adding weight to the diagnosis as the persistence of pyrexia despite treatment with antibiotics and antipyretics was characteristic. The presence of other symptoms during the course of the illness is not helpful in differentiating SARS from other viral infections with systemic manifestations; some of these symptoms may be attributed to the antimicrobials being administered.

Our findings on clinical examination suggest that most children with SARS will have some signs, but these are mild, and do not necessarily persist for the length of the illness. Most of the findings are in keeping with the systemic manifestations of any viral illness, but in addition there tends to be some mild crepitations throughout the lung fields.

Radiography of the chest is very important in the diagnosis of SARS, and all the P cases developed changes that did not correspond to any alteration in their clinical status. The paediatric population do not seem to develop the hypoxaemia associated with the onset of radiographic changes that has been the experience in the adult patients. ${ }^{8}$ There does not appear to be any change that cannot be associated with SARS, and so the only really helpful finding is of a normal chest radiograph, suggesting either a non-SARS diagnosis, or that the patient has presented early in the illness. The persistence of radiographic changes at outpatient follow up has not been seen in our population, and if present might suggest the possibility of an alternative diagnosis. The radiographic changes in four of these children have been described previously. ${ }^{9}$

There are significant haematological findings. Although leucopenia, lymphopenia, neutropenia, and thrombocytopenia can be seen in almost any viral illness, in our cohort the degree of suppression appears to be significantly greater, and occurs later in the course of the illness. The diagnosis that this often mimics is dengue, which has also recently increased in incidence in Singapore. None of our patients developed complications such as bleeding or secondary bacterial infection.

Specific coronavirus investigations such as PCR and serological assays may hold the key to rapid identification of SARS cases in the future, but at the time of writing these

Table 6 Haematological characteristics

\begin{tabular}{|c|c|c|c|c|c|c|c|c|}
\hline & \multicolumn{2}{|c|}{ Observed } & \multicolumn{2}{|c|}{ Suspect } & \multicolumn{2}{|c|}{ Probable } & \multicolumn{2}{|l|}{ All } \\
\hline & $\mathbf{n}$ & $\%$ & $n$ & $\%$ & $n$ & $\%$ & $n$ & $\%$ \\
\hline Anaemia $<120 \mathrm{~g} / \mathrm{l} \mathrm{Hb}$ & 10 & 0.24 & 10 & 0.43 & 3 & 0.43 & 23 & 0.32 \\
\hline Leucopenia WCC $<3.5 \times 10^{9} / \mathrm{I}$ & 3 & 0.07 & 0 & 0.00 & 5 & 0.71 & 8 & 0.11 \\
\hline Lymphopenia $<1.0 \times 10^{9} / 1$ & 4 & 0.10 & 1 & 0.04 & 2 & 0.29 & 7 & 0.10 \\
\hline Neutropenia $<1.0 \times 10^{9} / /$ & 3 & 0.07 & 1 & 0.04 & 3 & 0.43 & 7 & 0.10 \\
\hline Thrombocytopenia $<150 \times 10^{9} / /$ & 2 & 0.05 & 1 & 0.04 & 2 & 0.29 & 5 & 0.07 \\
\hline
\end{tabular}


investigations are themselves the subject of much research and discussion. In our cohort the diagnosis of SARS has been made on the basis of contact history, clinical features, radiographic changes and course of illness. In four patients the coronavirus investigations have confirmed the diagnosis. In those patients the stool and respiratory secretions have yielded a positive result, despite the blood PCR being negative. This finding is compatible with those previously described. At follow up two of the four patients had coronavirus detected in the stool by PCR, but there are no data to suggest the infectivity of this.

Although ribavarin and steroid therapy have been advocated for SARS we have not routinely used either. Ribavarin was given to five patients, but four had the treatment discontinued early as we felt that there was a lack of convincing data to support the practice. The one patient who completed the course presented at the beginning of the crisis when there was little data available. As none of our patients developed hypoxaemia there was no indication to use steroid therapy with the attendant risks. The mild clinical course and lack of oxygen requirement suggests that most patients will fully recover with only symptomatic treatment, and that aggressive medical treatment should be reserved for those patients with evidence of respiratory compromise.

The lack of morbidity, mortality, and intensive care admissions confirms that SARS in children is a relatively mild disease, with a high likelihood of complete recovery. The absence of nosocomial infections and transmission to healthcare workers gives us confidence in the current infection control practices within the isolation facilities, but also highlights the need to have ready access to such services for children with infectious diseases.

\section{Conclusions}

Within the paediatric cohort in Singapore, SARS has been a relatively mild illness. There are no extraordinary distinguishing clinical features of paediatric SARS. The presence of fever is characteristic, but the degree of pyrexia is not. Radiographic changes are usually present but their nature is variable. The children in our study have some degree of leucopenia, lymphopenia, neutropenia, and thrombocytopenia. All the children have fully recovered, most with symptomatic treatment.

\section{ACKNOWLEDGEMENTS}

The authors would like to thank all the medical, nursing, and support staff of Tan Tock Seng, National University, Singapore General, and KK Women's and Children's Hospitals for their hard work, dedication, and contribution to the fight against the SARS outbreak.

\section{Authors' affiliations}

J Puthucheary, D Lim, I Chan, O M Chay, Department of Paediatric Medicine, KK Women's and Children's Hospital, 100 Bukit Timah Road, Singapore 229899

P Choo, Tan Tock Seng Hospital, 11 Jalan Tan Tock Seng, Singapore 308433

\section{REFERENCES}

1 Peiris J, Lai S, Poon L, et al. Coronavirus as a possible cause of severe acute respiratory syndrome. Lancet 2003;361:1319-25.

2 Ksiazek TG, Erdman D, Goldsmith CS, et al. A novel coronavirus associated with severe acute respiratory syndrome. N Engl J Med 2003;348:1953-66

3 Lee N, Hui D, Wu A, et al. A major outbreak of severe acute respiratory syndrome in Hong Kong. N Engl J Med 2003;348:1986-94.

4 World Health Organisation. Cumulative number of reported probable cases of severe acute respiratory syndrome (SARS) [online]. Available at http:// www.who.int/entity/csr/sars/country/2003_07_11/en. Accessed 11 July 2003.

5 Hsu L-Y, Lee C-C, Green JA, et al. Severe acute respiratory syndrome (SARS) in Singapore: clinical features of index patient and initial contacts. Emerg Infect Dis 2003;9:713-17.

6 World Health Organisation. Case definitions for surveillance of severe acute respiratory syndrome (SARS) [online]. Available at http://www.who.int/csr/ sars/casedefinition (revised 1 May 2003). Accessed 11 July 2003.

7 Hon KL, Leung CW, Cheng WT, et al. Clinical presentations and outcome of severe acute respiratory syndrome in children. Lancet 2003;361:1701-3.

8 Kaw GJ, Tan DY, Leo YS, et al. Chest radiographic findings of a case of severe acute respiratory syndrome (SARS) in Singapore. Singapore Med J 2003;44:201-4.

9 Tsou IY, Loh LE, Kaw GJ, et al. Severe acute respiratory syndrome (SARS) in a paediatric cluster in Singapore. Pediatr Radiol 2003 Aug 20 [Epub ahead of print].

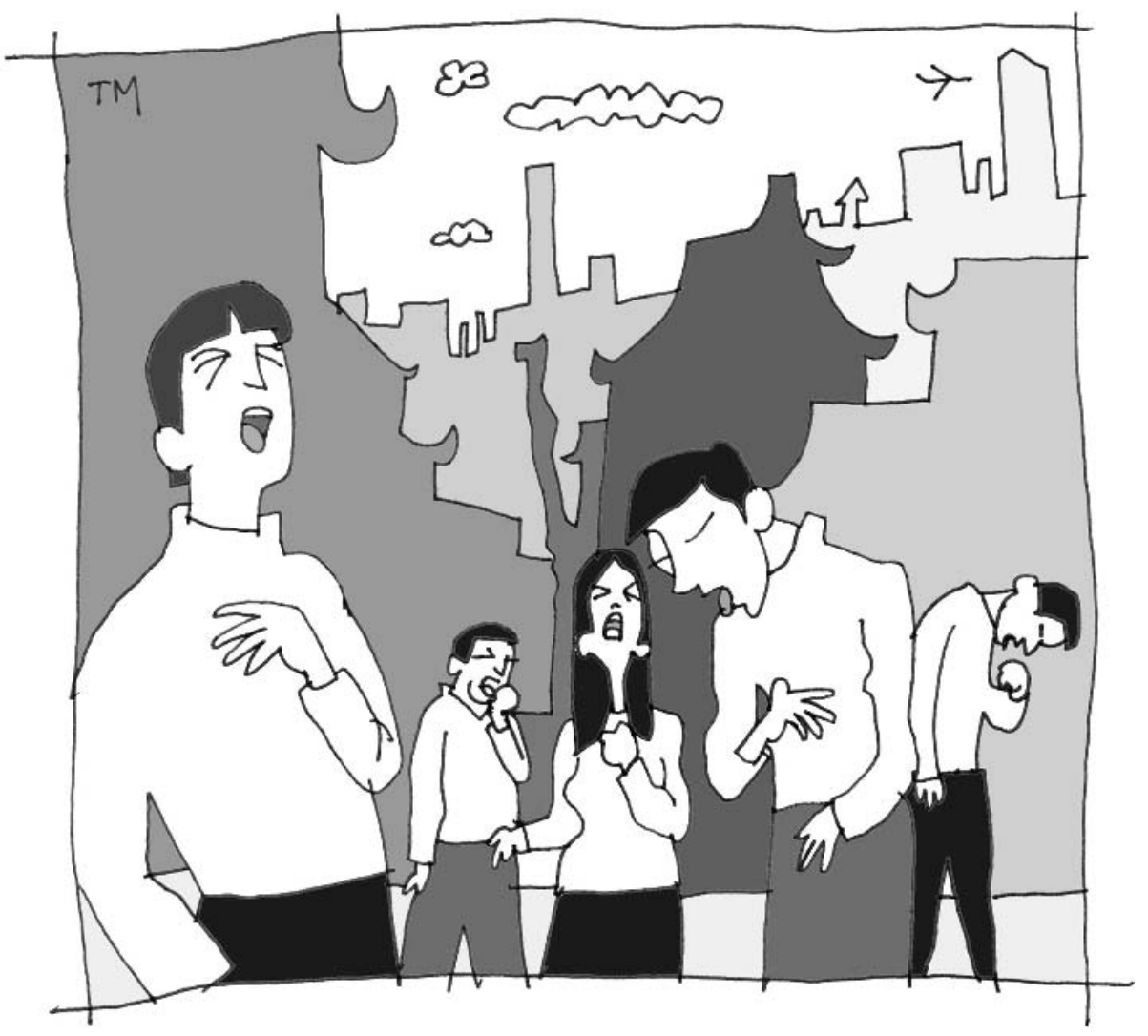

